\title{
Successful Factors and Prediction of Crowdfunding on WeChat
}

\author{
Yong Xu, Ni Zhu \\ School of Economics and Trade, South China University of Technology, Guangzhou, China \\ Email:dszhuni@foxmail.com
}

How to cite this paper: $\mathrm{Xu}, \mathrm{Y}$. and $\mathrm{Zhu}, \mathrm{N}$. (2018) Successful Factors and Prediction of Crowdfunding on WeChat. American Journal of Industrial and Business Management, 8, 946-962.

https://doi.org/10.4236/ajibm.2018.84065

Received: March 30, 2018

Accepted: April 25, 2018

Published: April 28, 2018

Copyright () 2018 by authors and Scientific Research Publishing Inc. This work is licensed under the Creative Commons Attribution International License (CC BY 4.0).

http://creativecommons.org/licenses/by/4.0/

\begin{abstract}
Taking crowdfunding projects on WeChat for research object, including Tencent Charitable Foundation and Qingsongchou, empirical study has used the multivariate analysis of variance, logistic regression and data mining to analyse the influence factors of final funding and the result (success or failure), and then build a model to forecast the result. The empirical study indicates that user participation, user trust and project characteristics have significant influence on crowdfunding projects' success. The forecast model based on data mining has good prediction accuracy.
\end{abstract}

\section{Keywords}

Crowdfunding, WeChat, Successful Factors, Logistic Regression, Forecast

\section{Introduction}

The Kickstarter is founded in 2009, which makes crowdfounding received wide attention in the world (Huang Jianqing and Xin Qiaoli, 2013) [1]. The first crowdfounding platform in China named Dianmingshijian was founded in 2011. Then crowdfounding platform is exploding in China. By the end of June 2017, China has about 808 crowdfounding platforms (Zhong Choujia, 2017) [2]. Griffin and Zachary (2012) [3] divide the type of crowdfounding into four categories according to the way of return on investment: Donate-based crowdfunding, Lending-based crowdfounding, Equity-based crowdfunding and Reward-based crowdfunding. Crowdfounding has become one of the hottest ways to raise money, and many countries have enacted laws to ensure their legitimacy. For example, the United States has passed the JOBS act in 2012, which ensures the legitimacy of the crowdfounding. Italy has passed the CONSOB act in 2013, which provides a tax support to crowdfounding (José Luis Sánchez García and 
Enrique Estellés-Arolas, 2015) [4]. In contrast, the crowdfounding in China is still in the immature stage, and the main problem is lack of legal supervision.

At present, a large amount of research has been done on crowdfunding in the world. In particular, for the qualitative research on WeChat crowdfunding, many scholars believe that the combination of WeChat and crowdfunding will bring disruptive results. In terms of the characteristics of WeChat crowdfunding, in addition to the features of modern crowdfunding itself, the WeChat platform has created a new advantage for crowdfunding. Most of people in WeChat are relatives, friends, classmates or colleagues. For fundraisers, he is familiar with crowdfunding users of WeChat friend circle. For crowdfunding users, every moment of fundraiser will be captured. So WeChat launchs a crowdfunding project often with high accuracy and authenticity, and WeChat has a perfect payment function making it easier for crowdfunding projects to raise funds (Zhao Zijun) [5]. In quantitative research on crowdfunding, scholars have studied crowdfunding activities on different crowdfunding platforms and established econometric models for empirical analysis. Empirical analysis of crowdfunding starts in the art field. Agrawal Agrawal, Catalini and Goldfarb (2015) [6] conduct an empirical analysis of the music platform Sellaband. For individual crowdfunding activities, research by Paul Belleflamme, Thomas Lambert and Armin Schwienbacher (2013) [7] shows that donated-based crowdfunding activities are more likely to succeed. And the larger the funding target, the more likely it will be to succeed. WeChat crowdfunding has various forms. It includes crowdfunding activities based on crowdfunding platforms and individual. WeChat possesses powerful payment system and social features. Therefore, it is significant to study crowdfounding on WeChat platform. We can give effective suggestions to the sponsor of crowdfunding and help them to raise the success rate of crowdfunding.

\section{Literature Review}

\subsection{User Participation}

Technology Acceptance Model is an important model to study the motivation of user participation. Many studies show that the Technology Acceptance Model can explain the user participation well in crowdfunding. Xu Chenfei and Chen Keqi (2015) [8] take Zhongchouwang (website) as the research object. The empirical results show that perceived risk has a significant impact on the participation of crowdfunding websites. Motivation theory is also an important model for studying the motivation of user participation. Fu Yaping and Zhao Xiaofei (2011) [9] from the perspective of network externality divide the participation motivation into entertainment motivation, social motivation and informative motivation. Based on the internal and external motivation framework, Kim, Shim and Ahn (2011) [10] divide the motivation into three major parts: extrinsic motivation, intrinsic motivation, and entertainment. The results show that entertainment has the greatest impact on user participation in SNS. 
In the research of Cai Yingying and Yue Zhonggang (2016) [11], the perceived risk includes funding period and funding target. The empirical results also show that funding period and the funding target have a significant impact on the success rate of the crowdfunding project. Ethan Mollick (2014) [12]'s research also proposed that funding target, funding period and user engagement have a significant impact on the success rate of the crowdfunding project. The research of Moutinho and Leite (2013) [13] indicates that project donors have a significant impact on the success rate of crowdfunding projects. In particular, there have different conclusions about the impact of the funding period on final funding. For example, in the study based on Jingdong (website) crowdfunding platform by Deng Jinwei (2016) [14], he believes that funding period is negatively related to the final funding. While $\mathrm{Wu}$ Wenqing, Fu Mingxia and Zhao liming (2016) [15] believe that funding period and final funding have an inverted $\mathrm{U}$-shaped relationship.

\subsection{User Trust}

User trust is an important factor which affects users "crowdfunding decisions". Participation in crowdfunding directly involves users' economic interests. If sponsor of crowdfunding project cannot obtain users' trust, it will be difficult to attract users to participate in crowdfunding projects. At present, the relevant laws of crowdfunding in our country are not perfect and cannot legally protect the interests of crowdfunding users. Moreover, for the crowdfunding platform in China, the crowdfunding types and forms are diverse. How to stand out from the crowdfunding projects and get users' trust is a very important factor that crowdfunding sponsor need to consider. User trust includes the social capital of sponsor, the size of sponsor team, and the successful experience of sponsor.

The most common reason for the failure of crowdfunding projects is that sponsor cannot attract enough investors (Jisun An, Daniele Quercia, and Jon Crowcroft, 2013) [16]. In Chen Yujie, Ni Ningxi and Gou Xiaoju (2015) [17]'s study, the empirical results show that the size of the project team significantly affects the crowdfunding results with the data of Zhuimengwang (website). In Li Jie (2015) [18]'s research, social capital of project sponsor is measured by three indicators: the number of Sina Weibo fans, the number of Zhuimengwang account points and the number of project comments. The results show that the project sponsor social capital has a significant effect on the result of crowdfounding. The study of Chen Huan (2015) [19] on the Zhuimengwang has verified the project sponsor social capital's impact.

\subsection{Project Characteristics}

Crowdfunding platforms operate mainly in the All-or-Nothing mechanism (AON) and the Keep-it-All mechanism (KIA). Under the AON mechanism, the project sponsor is success when they meet or exceed the funding target in the founding period, otherwise they are failed, and the project sponsor will need to return the funds. Under the KIA mechanism, the funds raised are available re- 
gardless of whether the project sponsor raises enough money to meet the funding target in founding period. There are different categories of projects in crowdfunding projects. The content display on the platform including video production and the number of pictures will have an impact on the project results.

In the study of Colombo, Franzoni and Rossi-Lamastra (2015) [20], project categories significantly affect crowdfunding success rates. While Ethan Mollick (2014) [12]'s study shows that project characteristics, videos, misspellings have a significant impact on funding levels. The study by Gafni et al. (2017) [21] propose that the project sponsor's description of the project had a significant impact on the success rate of crowdfunding. Kuppuswamy and Bayus (2013) [22]'s research on Kickstarter point out that information on crowdfunding projects has a significant impact on the success rate of crowdfunding. In the research of Zhang Yaodong (2015) [23], the quality of project information affects the result of financing. The quality of project information includes videos, texts and pictures. The research on Zhang Tianding and Hu Pinyang (2017) [24] also point out that the project quality signal has a positive effect on the financing efficiency of crowdfunding projects.

\section{Research Design}

\subsection{Research Scope}

The crowdfunding activities based on the WeChat platform vary in form, but it mainly can be divided into three forms. The first is through Tencent Charitable Foundation in WeChat wallet, the second is through WeChat official accounts, and the third is personal crowdfunding activities which mean sharing crowdfounding information into WeChat Moments. In the first form, Tencent Charitable Foundation is similar to the Zhongchouwang, Zhuimengwang and other standardized crowdfunding platform. Crowdfunding projects on Tencent Charitable Foundation are mainly donated-based crowdfunding. The project sponsor is divided into organization-initiated and individual-initiated. When the project sponsor meets funding target during funding period, the crowdfunding project is considered to be a success. In the second form, the most successful crowdfunding official account is Qingsongchou (crowdfunding official account on WeChat). Qingsongchou is different from Tencent Charitable Foundation. The crowdfunding projects on Qingsongchou are mainly return-based crowdfunding, and it most are individual-initiated. Crowdfunding projects on Qingsongchou generally within a funding period of one month, and the project sponsor is mainly through such crowdfunding channels to sell goods. In the third form, most of crowdfunding projects have no organization and have a small funding target. The third form of crowdfunding project is difficult to obtain data. Therefore, the third form of crowdfunding projects is beyond the scope of this article.

\subsection{Research Models and Hypothesis}

As can be seen from Figure 1, research model is based on three dimension: user 


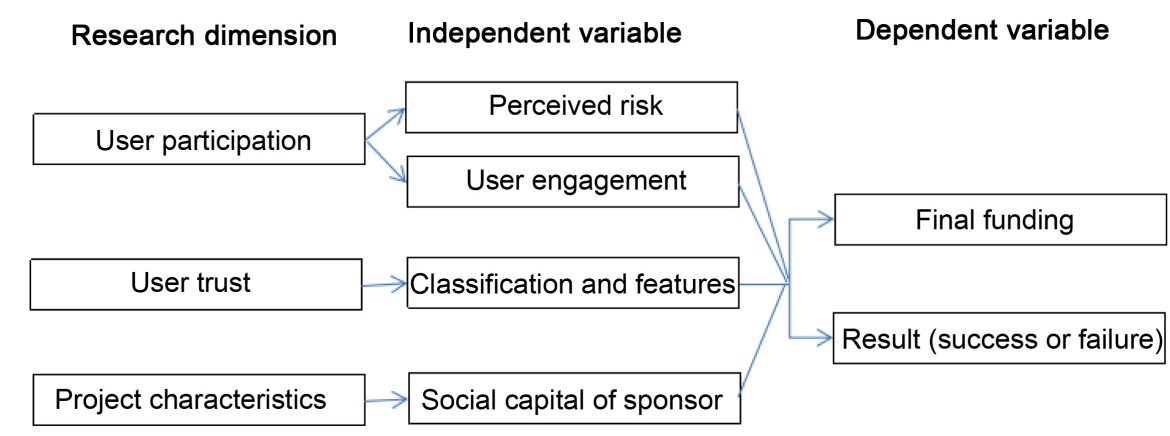

Figure 1. Research model.

participation, user trust and project characteristic. In the dimension of user participation, the project information of Tencent Charitable Foundation includes four items: funding period, funding target, the number of donations by normal way and the number of donations by Yiqijuan (another way to donate). Funding period means the time from the beginning to the end of the project, and it is generally very long. The dependent variable can be final funding of the project and the result (success or failure) of the project.

The user participation dimension include four variables on Qingsongchou: funding days, funding target, the number of donations and project forwarding numbers. Because all crowdfunding projects on Qingsongchou are managed by individual and the related information about sponsor can't be found, there are no variable in user trust dimension for Qingsongchou. In the dimension of project characteristics, the measurement is not the same due to the great differences between Tencent Charitable Foundation and Qingsongchou. In Tencent Charitable Foundation, the project characteristics include two categories of project classification and the number of labels for project, and there have three variables including classification, freight and delivery time for Qingsongchou.

Hypothesis 1: The funding period is curve-related to final funding.

Hypothesis 2: The funding target is positively related to final funding.

Hypothesis 3: The user engagement in crowdfunding projects is positively related to final funding.

Hypothesis 4: The sponsor identity has a significant impact on final funding and the success of the project.

Hypothesis 5: The project classification has a significant impact on final funding.

Hypothesis 6: For donated-based crowdfunding, the labels for projects have a significant impact on final funding and the success of the project.

Hypothesis 7: For return-based crowdfunding, the delivery time has a significant impact onfinal funding and the success of the project.

Hypothesis 8: For return-based crowdfunding, the freight has a significant impact on final funding and the success of the project.

To verify the above hypothesis, Empirical study has used the multivariate analysis of variance (MANOVA) and logistic regression and data mining. 
MANOVA is used in the research of the factors affect final funding, and logistic regression is used in the research of the factors affect the result (success or failure).

\subsection{Variable Description}

Table 1 is a detailed description of variables. It is also based on three dimensions: user participation, user trust and project characteristic.

\section{Empirical Results}

\subsection{The Source of Data}

Writing java program to get the project data of Tencent Charitable Foundation and Qingsongchou. There have total 6018 projects data of Tencent Charitable Foundation from June 2008 to March 2017. 177 projects data which lack of the funding target and 10 projects data that funding target are significantly deviated from the normal range (more than or equal to RMB 3 million or less than RMB 500 ) are eliminated. Finally 5831 valid data are obtained. The data effective rate is $96.9 \%$. There are 2472 successful projects, 3359 failed projects, so there have $42.4 \%$ successful projects. Most of crowdfunding projects in Qingsongchou are not completed. There have total 2333 projects data of Qingsongchou from January 2017 to March 2017. 35 projects data that funding target are significant deviation from the normal range (greater than or equal to RMB 100,000 or less than RMB 100) are eliminated. Finally 2298 valid data are obtained. The data efficiency is $98.5 \%$. Among them, a total of 307 projects are completed, including 148 successful projects, 159 failed projects, and there have $48.2 \%$ successful projects.

\subsection{Empirical Study for the Influence Factors of Final Funding}

In the research of the factors affect final funding raised by the crowdfunding on WeChat. Using multivariate analysis of variance (MANOVA) in the empirical

Table 1. Variable description.

\begin{tabular}{|c|c|c|}
\hline \multirow{2}{*}{ Dimension } & \multicolumn{2}{|c|}{ Variable } \\
\hline & Tencent Charitable Foundation & Qingsongchou \\
\hline \multirow{4}{*}{$\begin{array}{c}\text { User } \\
\text { participation }\end{array}$} & ln_day(funding period) & ln_R_day(funding days) \\
\hline & ln_need(funding target) & ln_need(funding target) \\
\hline & $\begin{array}{l}\text { ln_donateNum(donations by normal } \\
\text { way) }\end{array}$ & $\begin{array}{l}\text { ln_donateNum(the number of } \\
\text { donations) }\end{array}$ \\
\hline & ln_totalYqj(donations by YiQiJuan) & ln_forward(forwarding numbers) \\
\hline \multirow[t]{2}{*}{ User trust } & org( sponsor status) & None \\
\hline & & cateName(project classification) \\
\hline \multirow{2}{*}{$\begin{array}{c}\text { Project } \\
\text { characteristics }\end{array}$} & cateName(project classification) & freight(freight for goods) \\
\hline & n_label(project label number) & $\begin{array}{l}\text { deliveryTime(delivery time for } \\
\text { goods) }\end{array}$ \\
\hline
\end{tabular}


study because there are many categorical variables in certain dimensions. MANOVA is very useful to analyze whether a variable is affected by other factors. In many cases, there may be interactions between independent variables. MANOVA is also good at analyzing the interactions between independent variables.

\subsubsection{For Tencent Charitable Foundation}

The data of Tencent Charitable Foundation includes two categorical variables, organization (org) and project classification (cateName), and the project classification is not a dichotomous variable. When the funding period (day) and the square of the funding period $\left(\mathrm{day}^{\wedge} 2\right)$ are put together in the model to return final funding, the results are shown in Table 2. The coefficient of days is negative, and the coefficient of days $\wedge 2$ is positive. Both days and days $\wedge 2$ have a significant impact on the final funding. Therefore, there is a positive U-shaped curve between funding period and final funding.

Since the predecessors reached different conclusions in analyzing the impact of funding period on final funding, it can be judged based on the descriptive statistics of funding period and final funding. Figure 2 is the relationship between

Table 2. The influence of funding period on final funding.

\begin{tabular}{ccc}
\hline Parameter & $\beta$ & P-value \\
\hline Intercept & $49,519.442$ & 0.000 \\
Days & -252.990 & 0.000 \\
Days^2 & 1.483 & 0.000 \\
\hline
\end{tabular}

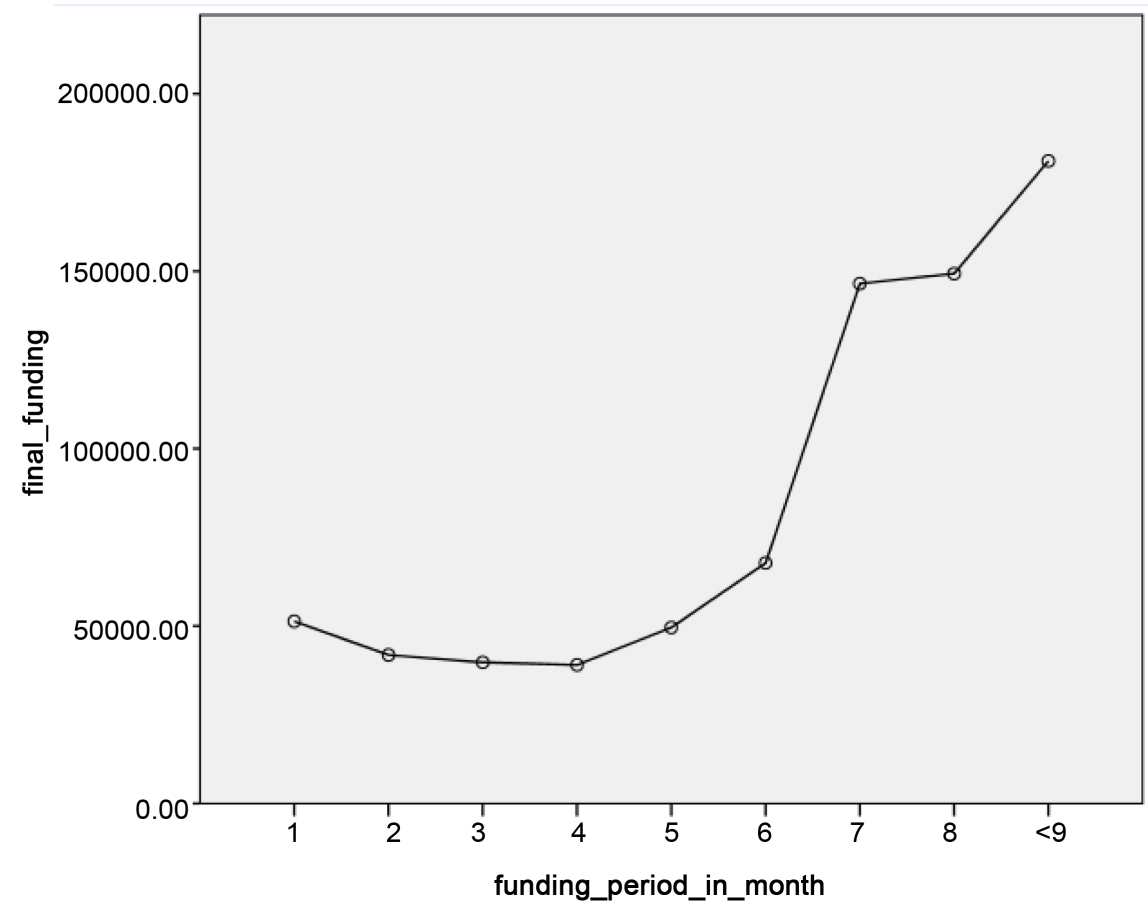

Figure 2. Relationship between final funding and funding period. 
final funding and funding period.

When funding period is less than four months, the average final funding will decrease with the increase of the funding period. However, when the funding period of the crowdfunding project exceeds four months, final funding will increase with the increase of funding period. In Tencent Charitable Foundation, funding period may be related to final funding with positive $\mathrm{U}$-shaped curve. From the perspective of success rate, as showed in Table 3, the success rate decreases as the funding period increases, and funding period within one month is the highest, reaching $88.48 \%$. The success rate of crowdfunding projects with a funding period of more than 3 months is very low, less than $10 \%$.

Studying the influence of the identity of the sponsor, descriptive statistical analysis can also be conducted first. The results are shown in Table 4. A total of 3994 projects are initiated by organization, accounting for $68.50 \%$ of the total, and 1837 projects are initiated by individual, accounting for $31.50 \%$. From the average final funding, the amount raised by individuals is higher than organization. However, from the perspective of project success rate, the success rate of the project initiated by organization reached $47.02 \%$, and the success rate of the individual-initiated project was $32.34 \%$. Therefore, the donation-based crowdfunding projects initiated by individuals actually raise more funds. In other word, donation-based crowdfunding are more suitable for initiation by individuals.

In the general model, each variable and the interaction items of cateName and org are examined in turn. As a result, it is found that the p-value of the interaction item is 0.077 . The remaining variables are all significant. Therefore, the interaction item is removed in the general model. Table 5 has shown the estimated coefficient of Tencent Charitable Foundation. The general model on Tencent Charitable Foundation is:

Table 3. The influence of funding period on success rate.

\begin{tabular}{cccccc}
\hline $\begin{array}{c}\text { Funding period } \\
(\text { month })\end{array}$ & $\begin{array}{c}\text { Project } \\
\text { numbers }\end{array}$ & $\begin{array}{c}\text { Average } \\
\text { funding }\end{array}$ & $\begin{array}{c}\text { Success } \\
\text { projects }\end{array}$ & $\begin{array}{c}\text { Success } \\
\text { rate }\end{array}$ & Percentage \\
\hline$<1$ & 2126 & $51,326.78$ & 1881 & $88.48 \%$ & $36.46 \%$ \\
$(1 \geq) \& \&(<3)$ & 1177 & $36,857.12$ & 448 & $38.06 \%$ & $20.19 \%$ \\
$(3 \geq) \& \&(<6)$ & 2381 & $35,401.95$ & 135 & $5.67 \%$ & $40.83 \%$ \\
$(\geq 6) \& \&(<12)$ & 131 & $120,176.63$ & 8 & $6.11 \%$ & $2.25 \%$ \\
$\geq 12$ & 16 & $134,061.66$ & 0 & $0.00 \%$ & $0.27 \%$ \\
\hline
\end{tabular}

Table 4. The influence of project sponsor's identity on success rate.

\begin{tabular}{cccccc}
\hline $\begin{array}{c}\text { Sponsor's } \\
\text { identity }\end{array}$ & $\begin{array}{c}\text { Project } \\
\text { numbers }\end{array}$ & $\begin{array}{c}\text { Average } \\
\text { funding }\end{array}$ & $\begin{array}{c}\text { Success } \\
\text { projects }\end{array}$ & Success rate & Percentage \\
\hline $\begin{array}{c}\text { Organization } \\
\text { Individual }\end{array}$ & 3994 & $42,862.35$ & 1878 & $47.02 \%$ & $68.50 \%$ \\
\hline
\end{tabular}


Table 5. Estimated coefficient of tencent charitable foundation.

\begin{tabular}{|c|c|c|c|c|}
\hline Variables & Model 1 & Model 2 & Model 3 & Model 4 \\
\hline Ln_day & $\begin{array}{l}-0.068^{\star} \\
(0.088)\end{array}$ & - & - & $\begin{array}{l}0.069^{\star} \\
(0.081)\end{array}$ \\
\hline Ln_day2 & $\begin{array}{c}-0.022^{* * *} \\
(0.001)\end{array}$ & - & - & $\begin{array}{c}-0.023^{* * *} \\
(0.001)\end{array}$ \\
\hline Ln_need & $\begin{array}{l}0.326^{* * *} \\
(0.000)\end{array}$ & - & - & $\begin{array}{c}0.352^{* * *} \\
(0.000)\end{array}$ \\
\hline Ln_donateNum & $\begin{array}{l}0.334^{* * *} \\
(0.000)\end{array}$ & - & - & $\begin{array}{c}0.336^{* * *} \\
(0.000)\end{array}$ \\
\hline Ln_totalYqj & $\begin{array}{c}0.385^{* * *} \\
(0.000)\end{array}$ & - & - & $\begin{array}{c}0.380^{* * *} \\
(0.000)\end{array}$ \\
\hline $\operatorname{Org}(=\mathrm{N})$ & - & $\begin{array}{c}0.124^{* * *} \\
(0.007)\end{array}$ & - & $\begin{array}{c}-0.098^{* * *} \\
(0.000)\end{array}$ \\
\hline $\begin{array}{l}\text { CateName(1) } \\
\text { (Poverty relief) }\end{array}$ & - & - & $\begin{array}{c}-0.327^{* * *} \\
(0.000)\end{array}$ & $\begin{array}{l}-0.012 \\
(0.769)\end{array}$ \\
\hline $\begin{array}{c}\text { CateName }(2) \\
\text { (Environmental/Animal } \\
\text { Protection) }\end{array}$ & - & - & $\begin{array}{l}0.377^{* *} \\
(0.016)\end{array}$ & $\begin{array}{l}-0.105 \\
(0.190)\end{array}$ \\
\hline $\begin{array}{l}\text { CateName(3) } \\
\text { (Disease relief) }\end{array}$ & - & - & $\begin{array}{c}0.595^{\star * *} \\
(0.000)\end{array}$ & $\begin{array}{l}-0.120^{* * *} \\
0.002\end{array}$ \\
\hline $\begin{array}{c}\text { CateName }(4) \\
\text { (Education/subsidy) }\end{array}$ & - & - & $\begin{array}{l}-0.067^{\star} \\
(0.377)\end{array}$ & $\begin{array}{l}-0.022 \\
(0.574)\end{array}$ \\
\hline
\end{tabular}

Note: The first row of each cell in the table represents the correlation coefficient, the second row represents the p-value of the significance test, and ${ }^{*},{ }^{* *}$, and ${ }^{* *}$ represent significant at the significant levels of $10 \%$, $5 \%$, and $1 \%$. CateName $=$ other parameters are redundant parameters, which means the coefficient is 0 .

$$
\begin{aligned}
& \text { receivedMoney }_{i j k} \\
& =\mu+\text { cateName }_{i}+\text { org }_{j}+\beta 1 * \ln \_ \text {day }_{k}+\beta 2 * \ln \_ \text {day } 2_{k}+\beta 3 * \ln \_ \text {need } \\
& \\
& +\beta 4 * \ln \_ \text {label }_{k}+\beta 5 * \ln \_ \text {donateNum } \\
&
\end{aligned}
$$

In model 1 , the impact of user participation on final funding is tested separately. $\ln \_$day is significant at the $10 \%$ significant level, and $\ln \_$day^ 2 is significant at the $1 \%$ significant level, indicating that funding period is related curvilinear to final funding, so Hypothesis 1 is established. The coefficients for ln_need, ln_donateNum, and ln_totalYqj are positive and significant at the $1 \%$ significance level, so Hypothesis 2 and Hypothesis 3 are established.

Model 2 separately examines the impact of user trust on final funding. The project sponsor is organization as the reference level. When the project sponsor is an individual, the coefficient is positive and significant at the $1 \%$ significant level, indicating the project sponsor's identity has a significant effect on final funding, and when the sponsor's identity is an individual, it is easier to raise more money, so Hypothesis 4 is established.

Model 3 separately examined the impact of project characteristics on final funding. Except that education/subsidy category is only significant at the $10 \%$ significant level, the remaining categories are all significant at the $1 \%$ significant 
level, indicating that project category has significant influence on final funding, so Hypothesis 5 is established. The coefficient of the number of project labels is negative, and it is significant at the 1\% level of significance, so Hypothesis 6 is established. The more the number of labels, the smaller funding to raise. Labeling a project is actually trying to attract people's attention, but it still lacks advantages compared to common crowdfunding projects.

All variables are added to model 4 , and the total model fit index was $73.5 \%$. It can be seen that except for some categories in the project category, the other variables are significant, indicating that the user participation, user trust, and project characteristics are all significant impact on final funding.

\subsubsection{For Qingsongchou}

Since the project of Qingsongchou contains three categorical variables. All variables and all three categorical variable interaction items are tested. The result shows that all variables are significant, but only the interaction items of freight and delivery time are significant in all interaction items. Table 6 has shown the estimated coefficient of Qingsongchou. So the general model on Qingsongchou is:

$$
\begin{aligned}
& \text { receivedMoney }{ }_{i j k l} \\
& =\mu+\text { cateName }_{i}+\text { freight }_{j}+\text { deliveryTime }_{k}+\text { freight }_{j} * \text { deliveryTime }_{k} \\
& +\beta 1 * \ln \_\mathrm{R} \_ \text {day }{ }_{l}+\beta 2 * \ln \_ \text {need } l+\beta 3 * \ln \_ \text {donateNum }{ }_{l} \\
& +\beta 4 * \ln \_ \text {forward } l+\varepsilon_{i j k l}
\end{aligned}
$$

Model 1 separately examines the impact of user participation on final funding. The coefficients for $1 n \_$need, $\ln \_$donateNum, and $\ln \_$forward are positive and significant at the $1 \%$ level, indicating that the project's funding target, user engagement are positively correlated to final funding, so Hypothesis 2 and Hypothesis 3 are established.

Model 2 separately examines the impact of project characteristics on final funding. The characteristics of the project include three dimensions: project category, freight and delivery time. Among them, the project category is based on the health care for reference level. Private kitchen and literary creation have a significant impact on final funding at a significant level of $1 \%$, verifying the establishment of Hypothesis 5. Freight is based on no mail for reference level, and delivery time is based on the delivery within a week (>one day) for reference level. The freight, delivery time and their interaction items all have a significant impact on final funding. Therefore, Hypothesis 7 and Hypothesis 8 are established.

In Model 3, all variables are added to the model. The total fitting index was 85.5\%. Except that some interaction items of delivery time and freight are not significant, other variables are significant, indicating project user participation and project characteristics have a significant effect on final funding.

\subsection{Empirical Study for the Influence Factors of the Success Rate}

In the research of the factors affect the result (success or failure) of crowdfunding 
Table 6. Estimated coefficient of Qingsongchou.

\begin{tabular}{|c|c|c|c|}
\hline Variables & Model 1 & Model 2 & Model 3 \\
\hline Ln_day & $\begin{array}{c}0.101^{\star * *} \\
(0.000)\end{array}$ & - & $\begin{array}{c}0.075^{\star * *} \\
(0.000)\end{array}$ \\
\hline Ln_need & $\begin{array}{c}0.117^{* * *} \\
(0.000)\end{array}$ & - & $\begin{array}{c}0.118^{* * *} \\
(0.000)\end{array}$ \\
\hline Ln_donateNum & $\begin{array}{c}0.920^{* * *} \\
(0.000)\end{array}$ & - & $\begin{array}{l}0.944^{* * *} \\
(0.000)\end{array}$ \\
\hline Ln_forward & $\begin{array}{c}0.082^{* * *} \\
(0.000)\end{array}$ & - & $\begin{array}{c}0.080^{* * *} \\
(0.000)\end{array}$ \\
\hline $\begin{array}{l}\text { CateName(1) } \\
\text { (Health) }\end{array}$ & - & $\begin{array}{c}0.028 \\
(0.910)\end{array}$ & $\begin{array}{c}0.675^{* * *} \\
(0.000)\end{array}$ \\
\hline $\begin{array}{l}\text { CateName(2) } \\
\text { (Grain and oil) }\end{array}$ & - & $\begin{array}{l}-0.058 \\
(0.551)\end{array}$ & $\begin{array}{c}-0.207^{\star * *} \\
(0.000)\end{array}$ \\
\hline $\begin{array}{l}\text { CateName(3) } \\
\text { (Fresh fruit) }\end{array}$ & - & $\begin{array}{l}-0.139 \\
(0.156)\end{array}$ & $\begin{array}{c}-0.223^{* * *} \\
(0.000)\end{array}$ \\
\hline $\begin{array}{c}\text { CateName }(4) \\
\text { (Private kitchen) }\end{array}$ & - & $\begin{array}{c}-0.348^{\star * *} \\
(0.003)\end{array}$ & $\begin{array}{c}-0.159^{* * *} \\
(0.001)\end{array}$ \\
\hline $\begin{array}{c}\text { CateName(5) } \\
\text { (Literary creation) }\end{array}$ & - & $\begin{array}{c}-0.548^{\star * *} \\
(0.000)\end{array}$ & $\begin{array}{c}0.351^{\star * *} \\
(0.000)\end{array}$ \\
\hline $\begin{array}{c}\text { Freight } \\
\text { (Free shipping) }\end{array}$ & - & $\begin{array}{l}1.138^{\star * *} \\
(0.000)\end{array}$ & $\begin{array}{c}0.282^{* * *} \\
(0.004)\end{array}$ \\
\hline $\begin{array}{l}\text { DeliveryTime(1) } \\
\text { (within one day) }\end{array}$ & - & $\begin{array}{c}-1.116^{\star *} \\
(0.040)\end{array}$ & $\begin{array}{c}-0.600^{* * *} \\
(0.008)\end{array}$ \\
\hline $\begin{array}{c}\text { DeliverTime (2) } \\
\text { (more than one week) }\end{array}$ & - & $\begin{array}{l}0.637^{\star *} \\
(0.050)\end{array}$ & $\begin{array}{c}0.326^{* * *} \\
(0.010)\end{array}$ \\
\hline $\begin{array}{l}\text { Freight }{ }^{*} \text { DeliveryTime } \\
\text { (free }^{*} \text { within one day) }\end{array}$ & - & $\begin{array}{l}1.146^{\star *} \\
(0.038)\end{array}$ & $\begin{array}{c}-0.648^{\star * *} \\
(0.004)\end{array}$ \\
\hline $\begin{array}{c}\text { Freight }{ }^{\star} \text { DeliveryTime } \\
\text { (free* more than one week) }\end{array}$ & - & $\begin{array}{c}-0.982^{* * *} \\
(0.005)\end{array}$ & $\begin{array}{l}-0.154 \\
(0.263)\end{array}$ \\
\hline $\mathrm{R}^{\wedge} 2$ & 0.839 & 0.036 & 0.855 \\
\hline
\end{tabular}

Note: The first row of each cell in the table represents the correlation coefficient, the second row represents the p-value of the significance test, and ${ }^{*},{ }^{*}$, and ${ }^{* *}$ represent significant at the significant levels of $10 \%$, $5 \%$, and $1 \%$. CateName $=$ other parameters are redundant parameters, which means the coefficient is 0 .

project on Tencent Charitable Foundation. The dependent variable is a categorical variable, and an ordinary linear regression model cannot be used. Therefore, Logistic regression is used. Non-numeric variables in the project data are quantified by defining dummy variables. The Logistic regression model is a logit transformation of the predictor's dependent variable, which makes a linear relationship between the transformed dependent variable and each independent variable.

\subsubsection{For Tencent Charitable Foundation}

In Tencent Charitable Foundation logistic regression model, the dependent variable is the result of the crowdfunding project (success_or_not). The crowd- 
funding project fails to have a code value of 0 and code for success is 1 . The poverty relief is reference level, the code for environmental/animal protection is cateName(1), the code for disease relief is cateName(2), the code for education/subsidy is cateName(3), and the others is cateName(4). In user trust dimension, the project initiated by the organization is coded as organization(1) with reference to an individual-initiated project. Table 7 is the logistic regression model for Tencent Charitable Foundation.

The coefficients for ln_day and ln_need are negative, and both are significant at a significant level of $1 \%$, indicating that the shorter funding period and the smaller funding target, the more likely the crowdfunding project will succeed. The coefficients of ln_donateNum and ln_totalYqj are positive and both are significant at the $1 \%$ significant level, indicating that the more users participate, the crowdfunding projects are more likely to succeed.

Org has a significant impact on the result of crowdfunding projects at the $1 \%$ level of significance. It can be seen from $\operatorname{Exp}(\mathrm{B})$ of $\operatorname{org}(1)$ that when the other factors remain unchanged, the project change from being initiated by an individual to organization, the success rate is increased by 1.5 times and is statistically significant, so Hypothesis 4 is established.

Both cateName and $n \_$label are significant at the $1 \%$ level, indicating that project characteristics have a significant effect on the result of crowdfunding projects. Therefore, Hypothesis 5 and Hypothesis 6 are established. According to $\operatorname{Exp}(\mathrm{B})$ of cateName, the success rate of the environmental/animal protection category is 3.2 times higher than the success rate of poverty relief. The success rate of the education/subsidy category is 3.4 times higher than poverty relief. The success rate of the others category is 2.5 times higher than poverty relief. And they all have statistical significance. While the success rate of the disease relief category is 1.1 times higher than poverty relief category, but it is not statistically significant. The coefficient of $n \_l a b e l$ is negative, indicating that the more

Table 7. Logistic regression model for Tencent charitable foundation.

\begin{tabular}{ccccccc}
\hline Variables & B & S.E, & Wals & df & Sig. & Exp (B) \\
\hline Ln_day & -1.989 & 0.065 & 949.723 & 1 & 0.000 & 0.137 \\
Ln_need & -1.021 & 0.059 & 297.668 & 1 & 0.000 & 0.360 \\
Ln_donateNum & 0.916 & 0.059 & 242.420 & 1 & 0.000 & 2.500 \\
Ln_totalYqj & 0.197 & 0.053 & 13.701 & 1 & 0.000 & 1.217 \\
CateName & - & - & 82.414 & 4 & 0.000 & - \\
CateName(1) & 1.155 & 0.331 & 12.188 & 1 & 0.000 & 3.173 \\
CateName(2) & 0.138 & 0.171 & 0.650 & 1 & 0.420 & 1.148 \\
CateName(3) & 1.229 & 0.166 & 54.484 & 1 & 0.000 & 3.417 \\
CateName(4) & 0.927 & 0.196 & 22.444 & 1 & 0.000 & 2.526 \\
N_label & -0.587 & 0.133 & 19.364 & 1 & 0.000 & 0.556 \\
Org(1) & 0.440 & 0.124 & 12.489 & 1 & 0.000 & 1.552 \\
Constant & 10.363 & 0.642 & 260.657 & 1 & 0.000 & $31,668.265$ \\
\hline
\end{tabular}


the number of project labels, the higher the project failure rate.

\subsubsection{For Qingsongchou}

In the Qingsongchou logistic regression model, the dependent variable is the result of the crowdfunding project (success_or_not). The crowdfunding project fails to have a code value of 0 and code for success is 1 . In the category of project (cateName), the health category is used as the reference level, the code for grain and oil is cateName(1), the code for fresh fruit is cateName(2), the code for private kitchen is cateName(3), and the code for literary creation is cateName(4), the health care code is cateName(5). For delivery time, delivery time more than one week is the reference level, the delivery code within one day is deliveryTime(1), and the delivery code within one week (>one day) is deliveryTime(2). For freight, the free shipping is the reference level, and the no mail is the freight (1). Table 8 is the logistic regression model for Qingsongchou.

The coefficient of ln_need is negative, and it is significant at the $1 \%$ significant level, indicating that the smaller funding target, the crowdfunding projects are more likely to succeed. The coefficients of $\ln \_$donateNum and $l n \_$forward are positive, and they are significant at the significant levels of $1 \%$ and $5 \%$, indicating that the more project participants, the more likely the success of crowdfunding projects.

Table 8. Logistic regression model for Qingsongchou.

\begin{tabular}{ccccccc}
\hline Variables & B & S.E, & Wals & df & Sig. & Exp (B) \\
\hline Ln_need & -2.478 & 0.411 & 36.282 & 1 & 0.000 & 0.084 \\
Ln_donateNum & 2.777 & 0.400 & 48.267 & 1 & 0.000 & 16.073 \\
Ln_forward & 0.450 & 0.205 & 4.801 & 1 & 0.028 & 1.568 \\
CateName & - & - & 5.537 & 5 & 0.354 & - \\
CateName(1) & 3.371 & 2.298 & 2.152 & 1 & 0.142 & 29.098 \\
CateName(2) & 3.432 & 2.299 & 2.229 & 1 & 0.135 & 30.941 \\
CateName(3) & 3.625 & 2.329 & 2.422 & 1 & 0.120 & 37.517 \\
CateName(4) & 4.729 & 2.424 & 3.805 & 1 & 0.051 & 113.201 \\
CateName(5) & 3.294 & 2.296 & 2.058 & 1 & 0.151 & 26.943 \\
Freight(1) & -1.461 & 1.672 & 0.763 & 1 & 0.382 & 0.232 \\
DeliveryTime & - & - & 0.166 & 2 & 0.920 & - \\
$\begin{array}{c}\text { DeliveryTime(1) } \\
\text { DeliveryTime(2) }\end{array}$ & 0.169 & 0.937 & 0.032 & 1 & 0.857 & 1.184 \\
$\begin{array}{c}\text { DeliveryTime* } \\
\text { freight }\end{array}$ & -0.038 & 0.847 & 0.002 & 1 & 0.964 & 0.963 \\
$\begin{array}{c}\text { DeliveryTime(1) by } \\
\text { freight(1) }\end{array}$ & 11.364 & 3.309 & 11.794 & 1 & 0.001 & $86,148.085$ \\
$\begin{array}{c}\text { DeliveryTime(2) by } \\
\text { freight(1) }\end{array}$ & 2.597 & 1.966 & 1.744 & 1 & 0.187 & 13.419 \\
Constant & 5.345 & 2.931 & 3.325 & 1 & 0.068 & 209.466 \\
\hline & & - & 12.199 & 2 & 0.002 & - \\
\hline & & & & & \\
\hline
\end{tabular}


The cateName, freight, and delivery time are not significant in the model, but the interaction items of the freight and delivery time are significant at the $1 \%$ level, indicating that the categories of crowdfunding products have no significant effect on the project success rate of Qingsongchou. The delivery time and freight of crowdfunding products have a significant effect on the success rate, so Hypothesis 7 and Hypothesis 8 are established. In the predictive analysis of the crowdfunding project, spss modeler (software) is used to establish a prediction model based on decision tree, BP-neural network, support vector machine and Bayesian belief network algorithm. $70 \%$ of the data is used as training set, $30 \%$ of the data is used as a test set, finally getting the accuracy of the prediction model. Due to the fact that when we make predictions for crowdfunding projects, we cannot obtain the specific circumstances of the number of project participants. Therefore, when we use data mining methods to make predictions on crowdfunding projects of Tencent Charitable Foundation and Qingsongchou, we eliminate the variable in user participation. The accuracy of the prediction model based on various algorithms is shown in Table 9.

\subsection{Predictive Analysis Based on Data Mining Methods}

In the predictive analysis of the crowdfunding project, spss modeler (software) is used to establish a prediction model based on decision tree, BP-neural network, support vector machine and Bayesian belief network algorithm. $70 \%$ of the data is used as training set, $30 \%$ of the data is used as a test set, finally getting the accuracy of the prediction model. Due to the fact that when we make predictions for crowdfunding projects, we cannot obtain the specific circumstances of the number of project participants. Therefore, when we use data mining methods to make predictions on crowdfunding projects of Tencent Charitable Foundation and Qingsongchou, we eliminate the variable in user participation. The accuracy of the prediction model based on various algorithms is shown in Table 9.

From Table 9, it can be seen that the decision tree model has a better prediction result for Tencent Charitable Foundation, and all the decision tree model prediction accuracy rate is over $88 \%$. The accuracy of the decision tree model based on C5.0 is $91.4 \%$, and the accuracy of the standard neural network model is $87.72 \%$. This shows that when the decision tree and neural network model are

Table 9. Predictive analysis based on data mining methods.

\begin{tabular}{ccc}
\hline Algorithm & $\begin{array}{c}\text { Accuracy on Tencent Charitable } \\
\text { Foundation (\%) }\end{array}$ & $\begin{array}{c}\text { Accuracy on } \\
\text { Qingsongchou (\%) }\end{array}$ \\
\hline CHAID & $88.68 \%$ & $47.42 \%$ \\
CART & $89.3 \%$ & $52.58 \%$ \\
C5.0 & $91.4 \%$ & $50.52 \%$ \\
BP-neural network & $87.72 \%$ & $49.48 \%$ \\
SVM & $59.08 \%$ & $54.64 \%$ \\
Bayesian belief network & $44.99 \%$ & $60.82 \%$ \\
\hline
\end{tabular}


used to predict the project results of the Tencent Charitable Foundation, there is a high accuracy, and the accuracy of the support vector machine and the Bayesian belief network is very low. On the Qingsongchou platform, the prediction accuracy of the Bayesian belief network algorithm is high, but it is only $60.82 \%$. This shows that for non-standard crowdfunding platforms, the results of individual-sponsored crowdfunding projects are difficult to predict. In a world, predictive analysis based on data mining methods has good accuracy.

\section{Conclusions}

This article takes the crowdfunding activities on WeChat as research object to study the influencing factors of the result of crowdfunding projects. The empirical analysis of Tencent charity and Qingsongchou are based on the three dimensions of user participation, user trust and project characteristics. The factors that affect the result of the project are calculated, and the data mining method is used to build a predictive model for the results of the crowdfunding project. The main conclusions and recommendations are as follows.

\subsection{The Funding Period Is Related Curvilinear to Final Funding}

According to the research on the influencing factors of final funding in Tencent Charitable Foundation, funding period is related curvilinear to final funding. More precisely it is $\mathrm{U}$-curve. The longer the funding period, the lower the success rate of the project. According to the descriptive statistics, when the funding period is within four months, the longer the funding period is, the less final funding will be. When the funding period exceeds four months, the longer the funding period, the more funds will be actually raised. Therefore, for small crowdfunding projects, the period for funding should be set as small as possible, which can be used to stimulate users to participate in crowdfunding and get more funding. It also can increase the success rate of the project.

\subsection{Donation-Based Crowdfunding Are More Suitable for Initiation by Individuals}

In the Tencent Charitable Foundation, the identity of sponsor has a significant impact on the success of crowdfunding projects. The average final funding of individual-initiated crowdfunding projects is about 45,000 yuan, and the average amount of funding projects initiated by organization is about 42,000 yuan. Therefore, the donation-based crowdfunding projects initiated by individuals actually raise more funds. However, the success rate of crowdfunding projects initiated by organization is higher. When the project sponsor changes from individual to organization, the success rate of the project is increased by about 1.5 times.

\subsection{Project Categories Have Different Influence on Crowdfunding Platform}

In the donation-based crowdfunding project, the project category has a signifi- 
cant impact on the success rate of the project. Poverty relief is used as a reference level, and the success rate of the education/subsidy category is approximately 3.4 times higher than poverty relief, and the success rate of the environmental/animal protection category is approximately 3.2 times higher than poverty relief. However, for return-based crowdfunding projects, the project category has no significant effect on the success rate of the project.

\subsection{Predictive Analysis Based on Data Mining Methods Has Good Accuracy}

For the standardized crowdfunding platform, the accuracy of the prediction using the decision tree and the BP-neural network algorithm is all above $88 \%$. Therefore, it is feasible to use the data mining method to establish the forecast model for crowdfunding project results. For non-standardized crowdfunding platform projects like Qingsongchou, since the projects are initiated by individual and the provided crowdfunding product information and personal information are not standardized, the prediction accuracy rate is generally low. Among them, the Bayesian algorithm has the highest forecast accuracy rate with only $60 \%$.

This article analyzes the factors affecting the success of crowdfunding projects of Tencent Public Welfare and Qingsongchou. In the project characteristics dimension, only the project classification and the number of project labels are studied in the Tencent Charitable Project, and only project classification, freight and delivery time are studied in Qingsongchou. In fact, the project characteristics should also include titles, pictures and texts contained in the project profile. The title and the content of each crowdfunding project convey different information to the user, which has a great influence on the success of the project. Therefore, the emotion dimension can be added to the research model to improve the research model.

\section{References}

[1] Huang, J.Q. and Xin, Q.L. (2013) The Concept, Characteristics and Enlightenment of the New Network Financing Model. International Finance, 9, 23-30.

[2] Zhong, C.J. (2017) China Crowdfunding Industry Development Report 2017. http://www.weiyangx.com/252174.html

[3] Griffin and Zachary (2012) Crowdfunding: Fleecing the American Masses. https://ssrn.com/abstract=2030001 https://doi.org/10.2139/ssrn.2030001

[4] García, J.L.S. and Estellés-Arolas, E. (2015) A Study of Present Creative Trends and Institutional Reaction. International Journal of Business and Economics, 14, 131-144.

[5] Zhao, Z.J. (2015) When WeChat Meets Crowdfunding-Thinking behind Subversive Entrepreneurship. E-Commerce, 20, 28-29.

[6] Agrawal, A., Catalini, C. and Goldfarb, A. (2015) Crowdfunding: Geography, Social Networks, and the Timing of Investment Decisions. Journal of Economics \& Management Strategy, 24, 253-274. https://doi.org/10.1111/jems.12093 
[7] Belleflamme, P., Lambert, T. and Schwienbacher, A. (2013) Individual Crowdfunding Practices. Venture Capital, 15, 313-333. https://doi.org/10.1080/13691066.2013.785151

[8] Xu, C.F. and Chen, K.Q. (2015) Research on Influencing Factors of Crowdfunding Website User Engagement-Taking Zhongchouwang as an Example. Information Magazine, 34, 175-182.

[9] Fu, Y.P. and Zhao, X.F. (2011) Research on User Participation Motivation and Participation Intensity of SNS Website Based on Network Effect. Finance and Trade Research, 6, 107-116.

[10] Kim, S. and Ahn. (2011) Social Networking Service: Motivation, Pleasure, and Behavioral Intention to Use. The Journal of Computer Information Systems, 51, 92-101.

[11] Cai, Y. and Yue, Z. (2016) Study on the Influencing Factors of Successful Crowd Funding Financing-Taking DianMingShiJian as an Example. Journal of Nanjing University of Posts and Telecommunications. Social Sciences Edition, 18, 53-62.

[12] Mollick, E. (2014) The Dynamics of Crowdfunding: An Exploratory Study. Journal of Business Venturing, 2, 1-16. https://doi.org/10.1016/j.jbusvent.2013.06.005

[13] Moutinho, N. and Leite, P. (2013) Sharing Information in a Virtual Community of Crowdfunding. The Case of Kickstarter. Fernanda Ribeiro, 1187-1207.

[14] Deng, J. (2016) The Influencing Factors of Crowdfunding Success: An Empirical Study Based on JingDong Crowdfunding Platform. International Business Accounting, 4, 91-96.

[15] Wu, W., Fu, M. and Zhao, L. (2016) Study on the Influencing Factors of Crowd Raising Success and Herding in China. Soft Science, 30, 5-8.

[16] An, J., Quercia, D. and Crowcroft, J. (2014) Recommending Investors for Crowdfunding Projects. In: Proceedings of the 23rd International Conference on World Wide Web, ACM, New York, 261-270. https://doi.org/10.1145/2566486.2568005

[17] Chen, Y., Ni, N. and Gou, X. (2015) Research on Influencing Factors of Crowdfunding Projects' Success or Failure in Innovation and Entrepreneurial Environment. Shanghai Economic Research, 11, 12-19.

[18] Li, J. (2015) Analysis of Factors Influencing the Success of Product-Raising Crowdfunding Project Financing. Commerce, 43, 191.

[19] Chen, H. (2015) Analysis on the Influencing Factors of Crowdfunding Project Success Based on Customer Value-Taking ZhuiMengWang as an Example. University of International Business and Economics, Beijing.

[20] Colombo, M.G., Franzoni, C. and Rossi-Lamastra, C. (2015) Internal Social Capital and the Attraction of Early Contributions in Crowdfunding. Entrepreneurship Theory \& Practice, 39, 75-100. https://doi.org/10.1111/etap.12118

[21] Gafni, H., Marom, D. and Sade, O. (2017) Are the Life and Death of an Early Stage Venture Indeed in the Power of the Tongue? Lessons from Online Crowdfunding Pitches. https://ssrn.com/abstract=2255707

[22] Kuppuswamy, V. and Bayus, B.L. (2013) Crowdfunding Creative Ideas: The Dynamics of Project Backers in Kickstarter. SSRN Electronic Journal, 5, 1-37.

[23] Zhang, Y. (2015) Crowdfunding Project Financing Influencing Factors Based on Consumer Perspective. Jiangsu University of Science and Technology, Zhenjiang.

[24] Zhang, T. and Hu, P. (2017) Analysis of Factors Affecting Crowdfunding Project Financing Efficiency. Soft Science, 31, 16-20. 